\title{
0802 SURVEILLANCE OF POISON INGESTION CASES AT PRINCE MSHIYENI MEMORIAL HOSPITAL, DURBAN, SOUTH AFRICA
}

R Paulsen*, D Swart Correspondence: Paraffin Safety Association of Southern Africa, 125 Belvedere Road, Claremont, Cape Town 7740, South Africa

\subsection{6/ip.2010.029215.802}

Introduction Internationally, poisonings are a major public health challenge. While accurate figures for intentional poisonings are limited, it is estimated that 350000 people died from unintentional poisonings globally in 2002 (WHO, 2004). The majority of these fatal injuries occurred in low- and middle-income countries. In 2006, the Paraffin Safety Association of Southern Africa developed an injury surveillance system monitoring household energy-related injuries in 14 healthcare institutions across South Africa.

Aim To study the injury surveillance data collected at Prince Mshiyeni Memorial Hospital with regard to the ingestion of poisons.

Methods The data were collected at the hospital between May 2006 and December 2009 by two volunteer community health workers interviewing patients and reviewing records.

Results Of the total 1480 energy-related injuries; 351 injuries related to poisoning. The data revealed that $93 \%$ of patients seeking treatment for poisoning were children younger than 10 years old. Alarmingly, babies between 1 and 2 years accounted for $55 \%$ of the total of those treated for poisoning. Gender differences were slight (females $46 \%$; males 54\%). The most commonly ingested poison was paraffin/kerosene (58\%). Nearly all ingestions occurred in the home (98\%) while the patient was playing (61\%). In most cases the outcome of the hospital visit concluded with the patient being treated and discharged. Conclusion The majority of patients treated for poisoning were babies and young children. The implementation of targeted interventions including health education and use of safe paraffin packaging in the home is crucial for decreasing the incidence of these preventable injuries. 